\title{
A review of executive function deficits in autism spectrum disorder and attention-deficit/ hyperactivity disorder
}

This article was published in the following Dove Press journal:

Neuropsychiatric Disease and Treatment

12 May 2016

Number of times this article has been viewed

\author{
Francesco Craig' \\ Francesco Margari ${ }^{2}$ \\ Anna R Legrottaglie' \\ Roberto Palumbi' \\ Concetta de Giambattista' \\ Lucia Margari' \\ 'Child Neuropsychiatry Unit, \\ 2Psychiatry Unit, Department of Basic \\ Medical Sciences, Neuroscience and \\ Sense Organs, University of Bari \\ "Aldo Moro", Bari, Italy
}

\begin{abstract}
Executive dysfunction has been shown to be a promising endophenotype in neurodevelopmental disorders such as autism spectrum disorder (ASD) and attention-deficit/ hyperactivity disorder (ADHD). This article reviewed 26 studies that examined executive function comparing ASD and/or ADHD children. In light of findings from this review, the ASD + ADHD group appears to share impairment in both flexibility and planning with the ASD group, while it shares the response inhibition deficit with the ADHD group. Conversely, deficit in attention, working memory, preparatory processes, fluency, and concept formation does not appear to be distinctive in discriminating from ASD, ADHD, or ASD + ADHD group. On the basis of neurocognitive endophenotype, the common co-occurrence of executive function deficits seems to reflect an additive comorbidity, rather than a separate condition with distinct impairments.
\end{abstract}

Keywords: executive function, autism spectrum disorder, attention-deficit/hyperactivity disorder, ASD + ADHD, neurocognitive endophenotype

\section{Introduction}

Executive function (EF) comprises a set of cognitive control processes, mainly supported by the prefrontal cortex, which regulates lower level processes (eg, perception, motor responses) and thereby enables self-regulation and self-directed behavior toward a goal, allowing us to break out habits, make decisions and evaluate risks, plan for the future, prioritize and sequence our actions, and cope with novel situations. ${ }^{1}$ Executive dysfunction has been shown to be a promising endophenotype in neurodevelopmental disorders, such as the autism spectrum disorder (ASD) ${ }^{2-4}$ and attention-deficit/ hyperactivity disorder (ADHD). ${ }^{5-8}$ Although there are important differences in core symptom definition, the co-occurrence between ASD and ADHD is supported by clinical, ${ }^{9-11}$ common biological, ${ }^{12-14}$ and nonbiological risk factors ${ }^{15-17}$ and neuroimaging studies. ${ }^{18,19}$

Several authors believe that ASD and ADHD share a common genetic basis. Both family ${ }^{20}$ and twin studies ${ }^{21}$ provide support for the hypothesis that ADHD and ASD originate from partly similar familial/genetic factors. Approximately $50 \%-72 \%$ of the contributing genetic factors in both disorders show overlap. ${ }^{22}$ These shared genetic and neurobiological underpinnings form an explanation why both disorders occur so frequently within the same patient and family. Recent genetic evidences suggest that synaptosomal-associated protein of $25 \mathrm{kDa}$ is involved in ASD and ADHD. ${ }^{23} \mathrm{In}$ line with these observations, studies have reported significant correlations between 
single nucleotide polymorphisms of synaptosomal-associated protein of $25 \mathrm{kDa}$ and one or more aspects of the EF. ${ }^{24,25}$ Both ADHD and ASD are childhood-onset neurodevelopmental disorders affecting key frontostriatal and frontoparietal circuits that are important for EF. ${ }^{8}$ A better understanding of the neurocognitive endophenotype of the co-occurrence of ASD + ADHD is important because it could not only provide clues for enhanced treatment options but could also highlight the existence of a combined phenotype.

EF impairments have been considered as central deficits in ADHD or ASD. It has traditionally been argued that the EF deficits, such as deficit in response inhibition or working memory (WM) and overall weakness in executive control, are related to ADHD symptoms. Pennington and Ozonoff reported minimal evidence of an association between EF and ADHD suggesting that additional research was needed to test whether the relation between ADHD and EF was significant in the general population or was a sampling artifact restricted to clinic-referred samples. ${ }^{26}$ Barkley proposed the hypothesis that ADHD symptoms may be due to EF deficits. Based on Barkley's model, ADHD-combined (ADHD-C) subtype is related to deficits in EFs, but there is no EF deficit for ADHD-inattentive (ADHD-I) subtype. ${ }^{5}$ On the contrary, a review of differences in ADHD subtypes suggests that ADHD-C is more characterized by a lack of inhibitory control, whereas ADHD-I is more characterized by sluggish, disorganized behavior. ${ }^{27}$ Willcutt et al in a meta-analysis of 83 studies stated that ADHD children/adolescents exhibited significant deficits compared to those without ADHD in neuropsychological measures of EF, such as planning, spatial and verbal WM, response inhibition, and vigilance. ${ }^{8}$ Gargaro et al described that tasks measuring inhibition are by no means the only method for demonstrating cognitive deficits in children with ADHD. ${ }^{28}$ Consistent deficits have been reported for a number of other cognitive tasks, such as those measuring sustained attention. Furthermore, individuals with ADHD display longer reaction times and more omission and commission errors than controls. Recently, Ahmadi et al studied the possibility of iconic memory impairment in children with ADHD and found that visual memory is weaker in children with ADHD and they have weaker memory performance than normal children with both visual and auditory symbols at $50 \mathrm{~ms}$ and $100 \mathrm{~ms}$ presentation durations. ${ }^{29}$

Over time, researchers have shown an increased interest in executive dysfunction of children with ASD. Among the models that try to identify the primary deficit in ASD, a significant role is played by the assumption that a disturbance at the level of the EFs may be causing many autism symptoms. ${ }^{2-4}$ Early studies investigated the EF in high-functioning autism, especially in the domain of cognitive flexibility, planning, and WM. In all situations, both in studies with children and adolescents, ${ }^{2,3}$ people with autism have manifested constant impairments of EFs. Several studies revealed difficulties with planning, and cognitive flexibility was often observed in the form of perseverative errors in this population. ${ }^{30,31}$ In addition to perseverative errors, children with autism have also shown more deficits in shifting attention, ${ }^{32}$ sustained or selective attention, ${ }^{33}$ and response inhibition. ${ }^{34,35}$ The review by Hill et al on EF in ASD highlights impairments (vs typically developing [TD] controls) on at least two key aspects of EF: planning (eg, anticipatory grasp, Tower of Hanoi/ London, detour reaching) and flexibility (eg, Wisconsin Card Sorting Test [WCST], extradimensional shift of the ID/ED task). ${ }^{36}$ In a recent review of EF in autism, O'Hearn et $\mathrm{al}^{37}$ indicated impairments in tasks requiring response inhibition, WM, planning, and attention, which appear to be present also in adulthood.

While previous studies have documented EF impairments in ADHD and ASD separately, in recent years, a considerable amount of literature has grown up around the EF deficit directly comparing ASD and ADHD. In light of such literature, the aim of this review was to examine the similarities and differences in executive functioning between ASD and ADHD in order to identify neurocognitive endophenotypes, which could support the eventual existence of a clinical combined phenotype (ASD + ADHD). Here we review various domains of EF through neurocognitive tasks found in both the pediatric ASD and ADHD literature. To the best of our knowledge, this is the first review on EFs comparing exclusively ASD and ADHD groups. We discuss similarities and differences in ASD and ADHD and their implications for common or differential diagnosis of these two disorders. We also analyze the executive functioning of ASD + ADHD phenotype.

Through this review, we examine different hypotheses:

1. ASD + ADHD is a distinct phenotype from ASD or ADHD phenotype.

2. $\mathrm{ASD}+\mathrm{ADHD}$ phenotype represents the co-occurrence of the two disorders.

3. ADHD and ASD represent two separate spectrums with some overlapping.

Efforts to define the common or distinct neurocognitive endophenotype of these disorders may help to refine classification systems and enhance the assessment of these complex cases for more specific treatment strategies. 


\section{Methods}

\section{Search strategy}

The literature search was conducted through PubMed, EBSCOhost, Elsevier, Scopus, and Web of Science using a combination of the following free-text terms: "Executive Function", "autism spectrum disorders", "autism", "ASD", "Attention Deficit Hyperactivity Disorder", “ADHD”, and "pervasive development disorder".

\section{Inclusion criteria}

The studies included in this review met the following five criteria: 1) compared ASD vs ADHD; 2) assessed EF skills through standardized test; 3 ) enrolled child and adolescent patients (from 3 years to 18 years of age); 4) were published in English; and 5) were published in peer-reviewed journals. No other restrictions (eg, date of publication) were applied. Review articles and anecdotal clinical reports were excluded.

\section{Data extraction}

Studies that met the inclusion criteria were summarized in terms of: 1) participants (sample characteristics and sample size); 2) specific EF; 3) assessment procedure; and 4) results. The first author performed data extraction from the included studies, while an independent rater checked for accuracy. In cases of disagreement on the extracted data, articles were reexamined until consensus (100\% agreement) was reached.

\section{Interobserver agreement}

A total of 45 articles were identified from the initial search strategies. Each of these 45 articles was then examined, resulting in 26 articles that were retained for screening against the inclusion criteria by two independent reviewers. Agreement as to whether or not the study met the inclusion criteria was $100 \%$.

\section{Results}

Table 1 provides a summary of the 26 studies that investigated EF deficits comparing ASD and ADHD. The studies are ordered by date of publication and are categorized by the number of participants, diagnosis-related groups, intelligence quotient (IQ), age range, and EF evaluated.

\section{Characteristics of participants}

All studies involved children with ASD and children with ADHD, with a total of 646 and 789, respectively; furthermore, five studies included ASD + ADHD group in which 101 individuals met the diagnostic criteria for both ASD and ADHD. All studies have used previous versions of the Diagnostic and Statistical Manual of Mental Disorders, Fifth Edition, for diagnosis. TD controls were also examined in 23 studies enrolling a total of 723 children with this condition.

The age of the children ranged from 3 years to 18 years. Twenty-three studies included children between 6 years and 18 years of age, while three studies also examined children $<6$ years of age.

Nine studies included children with IQ scores within the normal range ( $\geq 80-85$ IQ points), 14 studies also included children with IQ scores within the borderline range ( $\geq 70-75$ IQ points), and only one study also involved children with IQ scores within the mild disability range ( $\geq 60-65$ IQ points). Two studies did not report the IQ level.

\section{Specific EF}

Twenty-two studies examined response inhibition, fourteen studies examined the WM, thirteen studies examined flexibility, eleven studies examined different domains of attention, nine studies examined planning, four studies examined monitoring, three studies examined preparatory processing, two studies examined fluency, and one study examined concept formation (Table 1).

\section{Procedures to assess EF deficits}

Assessment of EFs involves gathering data from several sources and synthesizing the information to look for trends and patterns across time and setting. Apart from formal tests, other measures such as standardized checklists, observations, interviews, and work samples could be used. We found several different kinds of assessment tools to assess EF, which included parent/teacher reports, computerized cognitive tests, and performance-based tests measuring EFs in children with ASD and ADHD. The most common questionnaire developed for parents was the Behavior Rating Inventory of Executive Function, which was used in five studies to assess inhibition, attention, WM, flexibility/shifting, planning, preparatory processing, monitoring, and fluency..$^{38-42}$ The Cambridge Neuropsychological Test Automated Battery was used in five studies to assess attention, WM, flexibility/shifting, and planning. ${ }^{43-47}$ The Go/No-Go and the Stroop tests were used in ten and seven studies, respectively, to assess inhibition response. Among the performance-based tests, five studies used the WCST in order to assess inhibition, WM, flexibility/shifting, planning, and concept formation. Table 2 reports the assessment tools used in the studies included in this review. 
Table I Features of the 26 studies reviewed

\begin{tabular}{|c|c|c|c|c|c|}
\hline Study & $\begin{array}{l}\text { Number of } \\
\text { participants (n) }\end{array}$ & Diagnosis-related groups & IQ & $\begin{array}{l}\text { Age range, } \\
\text { years }\end{array}$ & EF evaluated \\
\hline Lawson et al ${ }^{42}$ & 125 & 70 ASD, 55 ADHD & $\mathrm{IQ} \geq 70$ & $6-16$ & Response inhibition, flexibility \\
\hline Samyn et $\mathrm{al}^{52}$ & 209 & 3I ASD, 30 ADHD, I48 TD & $\mathrm{IQ} \geq 80$ & $10-15$ & Response inhibition and attention \\
\hline Matsuura et al ${ }^{43}$ & 45 & Eleven ASD, 15 ADHD, 19 TD & $\mathrm{IQ} \geq 75$ & $8-13$ & Attention and WM \\
\hline Sinzig et $\mathrm{a}^{58}$ & 87 & 28 ASD, 30 ADHD, 29 TD & $\mathrm{IQ} \geq 70$ & $4-9$ & $\begin{array}{l}\text { Response inhibition, flexibility, } \\
\text { attention }\end{array}$ \\
\hline Hovik et $\mathrm{al}^{39}$ & 179 & $\begin{array}{l}19 \text { TS, } 33 \text { ADHD-C, } 43 \text { ADHD-I, } \\
34 \text { ASD, } 50 \text { TD }\end{array}$ & $\mathrm{IQ} \geq 70$ & $8-12$ & $\begin{array}{l}\text { Response inhibition, WM, planning, } \\
\text { monitoring }\end{array}$ \\
\hline Samyn et $a^{162}$ & 65 & 24 ADHD, 20 ASD, 21 TD & $\mathrm{IQ} \geq 80$ & $10-15$ & Attention \\
\hline Tye et $\mathrm{a}^{60}$ & 92 & $\begin{array}{l}19 \text { ASD, } 18 \text { ADHD, } 29 \text { ASD + } \\
\text { ADHD, } 26 \text { TD }\end{array}$ & $\mathrm{IQ} \geq 70$ & $8-13$ & $\begin{array}{l}\text { Response inhibition, attention, } \\
\text { preparatory processing, } \\
\text { monitoring }\end{array}$ \\
\hline Yasumura et $\mathrm{a}^{55}$ & 36 & Ten ADHD, eleven ASD, I5 TD & $\mathrm{IQ} \geq 80$ & $8-13$ & Response inhibition \\
\hline Salcedo-Marin et $\mathrm{al}^{41}$ & 103 & 80 ADHD, 23 ASD & $\mathrm{IQ} \geq 70$ & $8-17$ & $\begin{array}{l}\text { Attention, WM, response } \\
\text { inhibition, preparatory processing }\end{array}$ \\
\hline Takeuchi et al ${ }^{56}$ & 104 & $\begin{array}{l}20 \text { ADHD, } 16 \text { ASD + ADHD, } \\
\text { eight ASD, } 60 \text { TD }\end{array}$ & $\mathrm{IQ} \geq 80$ & $6-15$ & Response inhibition, WM \\
\hline Xiao et $\mathrm{al}^{50}$ & 51 & 19 ASD, 16 ADHD, 16 TD & $\mathrm{IQ} \geq 80$ & $8-12$ & Response inhibition \\
\hline Kado et $\mathrm{al}^{57}$ & 150 & 52 ASD, 46 ADHD, 52 TD & $\mathrm{IQ} \geq 80$ & $5-15$ & $\begin{array}{l}\text { Response inhibition, attention, } \\
\text { WM, concept formation }\end{array}$ \\
\hline Semrud-Clikeman et al ${ }^{40}$ & 96 & $\begin{array}{l}\text { I5 ASD, } 2 \text { I ADHD-C, } 28 \text { ADHD- } \\
\text { PI, } 32 \text { TD }\end{array}$ & $\mathrm{IQ} \geq 80$ & $9.1-16.5$ & $\begin{array}{l}\text { Response inhibition, planning, WM, } \\
\text { flexibility, monitoring }\end{array}$ \\
\hline Corbett et $\mathrm{al}^{44}$ & 54 & I8 ASD, I8 ADHD, I8 TD & $\mathrm{IQ} \geq 70$ & $7-12$ & $\begin{array}{l}\text { Response inhibition, WM, } \\
\text { flexibility, planning, fluency, } \\
\text { attention }\end{array}$ \\
\hline Gomarus et a ${ }^{59}$ & 60 & $\begin{array}{l}\text { I5 ASD, } 15 \text { ADHD, } 15 \text { ASD + } \\
\text { ADHD, I5 TD }\end{array}$ & $\mathrm{IQ} \geq 70$ & $8-11$ & Attention, WM \\
\hline Yang et al ${ }^{54}$ & 76 & 20 ASD, 26 ADHD, 30 TD & - & $3.7-15.8$ & $\begin{array}{l}\text { Response inhibition, WM, } \\
\text { flexibility }\end{array}$ \\
\hline Sinzig et $\mathrm{al}^{53}$ & 101 & $\begin{array}{l}30 \text { ADHD, 2I ASD + ADHD, } \\
20 \text { ASD, } 30 \text { TD }\end{array}$ & $\mathrm{IQ} \geq 75$ & $6-18$ & Response inhibition, attention \\
\hline Sinzig et $\mathrm{a}^{45}$ & 80 & $\begin{array}{l}20 \text { ADHD, } 20 \text { ASD, } 20 \text { ASD + } \\
\text { ADHD, } 20 \text { TD }\end{array}$ & $\mathrm{IQ} \geq 80$ & $6-18$ & $\begin{array}{l}\text { Response inhibition, flexibility, } \\
\text { WM, planning }\end{array}$ \\
\hline Johnson et $\mathrm{al}^{61}$ & 62 & 23 ADHD, 2I ASD, 18 TD & $\mathrm{IQ} \geq 70$ & $8-12$ & Attention \\
\hline Happé et $\mathrm{al}^{46}$ & 94 & 32 ASD, 30 ADHD, 32 TD & $\mathrm{IQ} \geq 69-70$ & $8-16$ & $\begin{array}{l}\text { Response inhibition, flexibility, } \\
\text { planning, WM }\end{array}$ \\
\hline Goldberg et $\mathrm{a}^{47}$ & 70 & I7 ASD, 2 I ADHD, 32 TD & $\mathrm{IQ} \geq 75$ & $8-12$ & $\begin{array}{l}\text { Response inhibition, flexibility, } \\
\text { planning, WM }\end{array}$ \\
\hline Tsuchiya et al ${ }^{49}$ & 59 & 17 ASD, 22 ADHD, 25 TD & $\mathrm{IQ} \geq 70$ & $8-16$ & $\begin{array}{l}\text { Response inhibition, attention, } \\
\text { flexibility }\end{array}$ \\
\hline Geurts et $\mathrm{al}^{48}$ & 136 & 54 ADHD, 4I ASD, 4I TD & $\mathrm{IQ} \geq 80$ & $6-12$ & $\begin{array}{l}\text { Response inhibition, WM, planning, } \\
\text { flexibility, fluency }\end{array}$ \\
\hline Gioia et a ${ }^{38}$ & 141 & $\begin{array}{l}27 \text { ADHD-IT, } 26 \text { ADHD-CT, } \\
54 \text { ASD, } 34 \text { RD, } 34 \text { TBI }\end{array}$ & $\mathrm{IQ} \geq 65$ & $8-15$ & $\begin{array}{l}\text { Response inhibition, WM, } \\
\text { flexibility, planning, preparatory } \\
\text { processing, monitoring }\end{array}$ \\
\hline Nyden et $\mathrm{al}^{51}$ & 20 & Ten ASD, ten ADHD, ten TD & - & $8-11$ & Response inhibition \\
\hline Ozonoff and Jensen ${ }^{35}$ & 123 & 40 ASD, 24 ADHD, 30 TS, 29 TD & $\mathrm{IQ} \geq 70$ & $10-15$ & $\begin{array}{l}\text { Planning, flexibility, response } \\
\text { inhibition }\end{array}$ \\
\hline
\end{tabular}

Abbreviations: IQ, intelligence quotient; EF, executive function; ASD, autism spectrum disorder; ADHD, attention-deficit/hyperactivity disorder; TD, typically developing; WM, working memory; ADHD-C, ADHD-combined; ADHD-I, ADHD-inattentive; TS, tourette syndrome; ADHD-PI, ADHD-predominately inattentive; ADHD-IT, ADHDinattentive type; ADHD-CT, ADHD-combined type; RD, reading disorders; TBI, traumatic brain injury.

\section{Similarities and differences in EF}

The results of EF pertain to the following domains: inhibition, WM, flexibility, attention, planning, monitoring, preparatory processing, fluency, and concept formation. Table 3 reports the comparison of EF deficits between ASD, ADHD, ASD + ADHD, and TD groups.

\section{Inhibition response}

Five studies detected statistical significant differences in inhibition response between ASD and ADHD groups compared to the TD group. ${ }^{40,48-51}$ No significant differences between ASD, ADHD, and TD groups on inhibit performances were found in five studies. ${ }^{41,47,52-54}$ In three studies, ADHD 


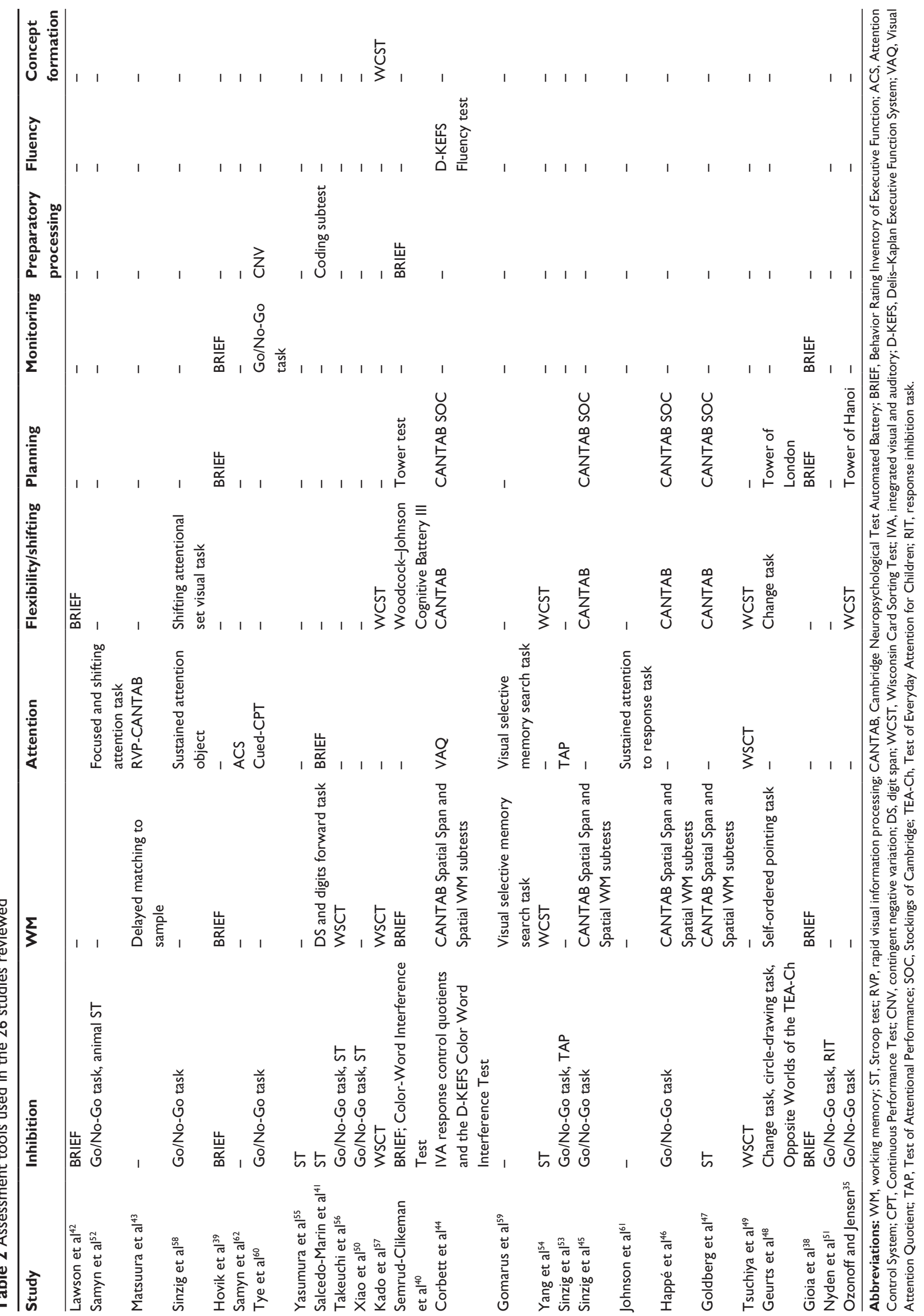



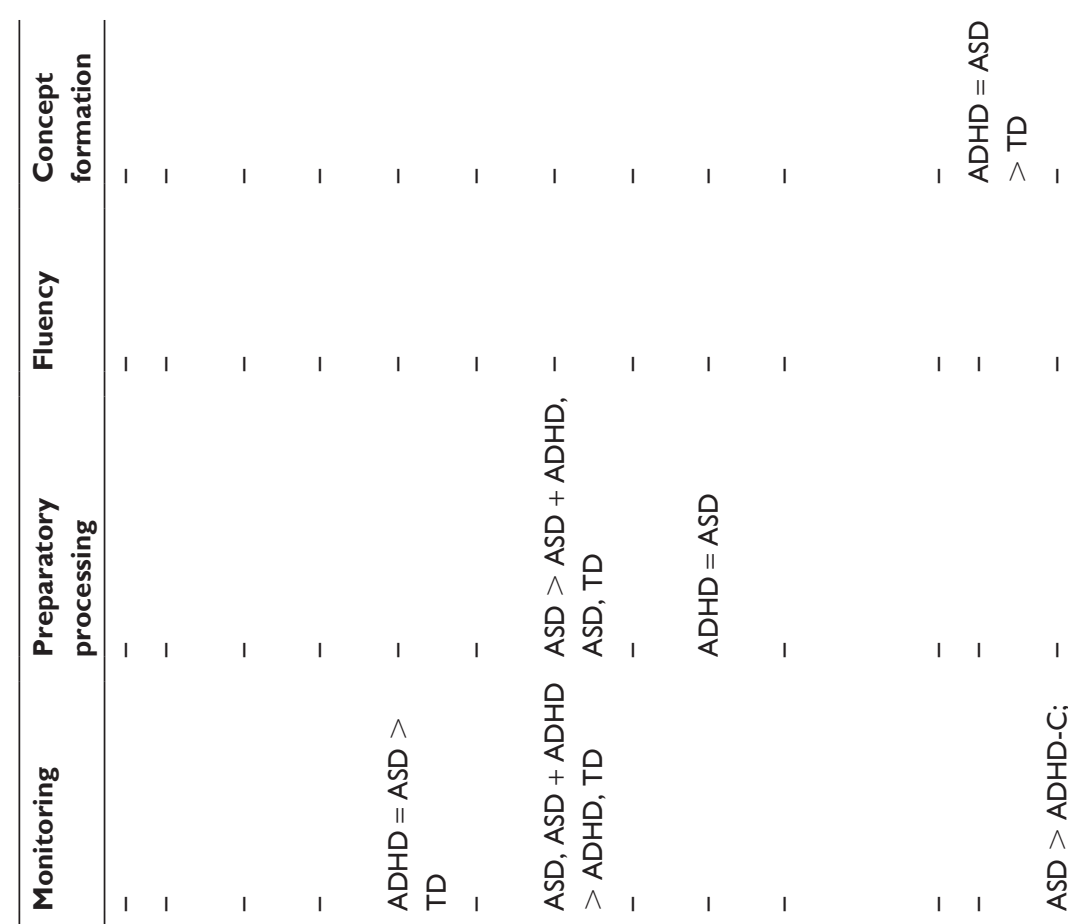

号
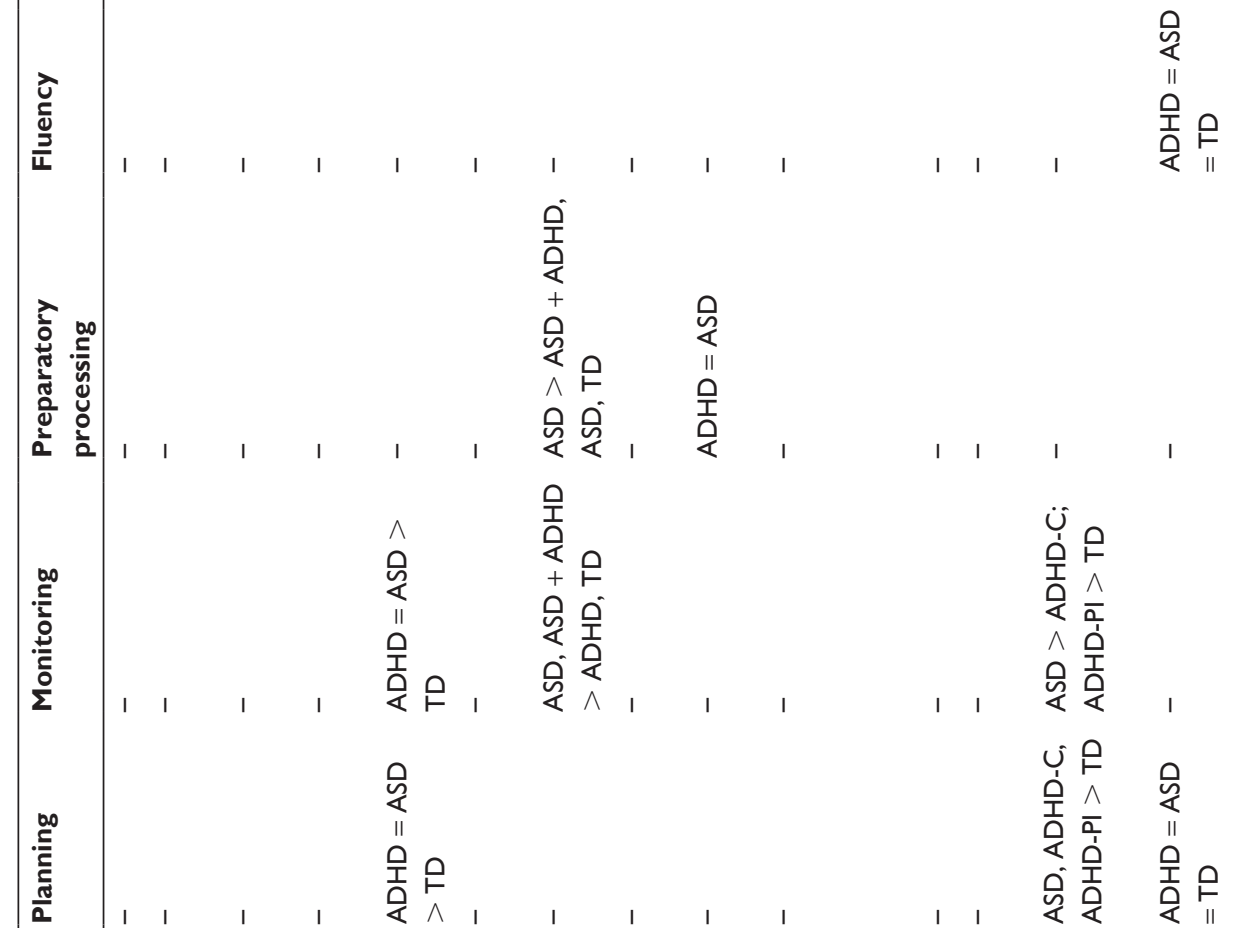

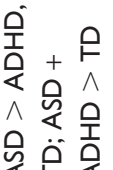

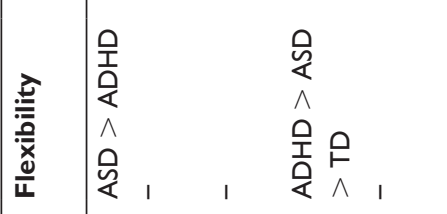

\section{울}

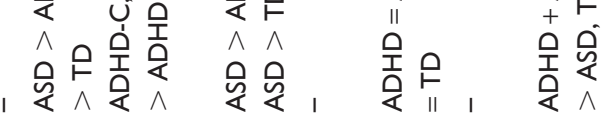

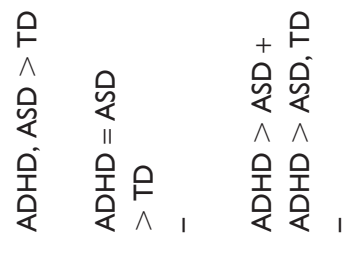

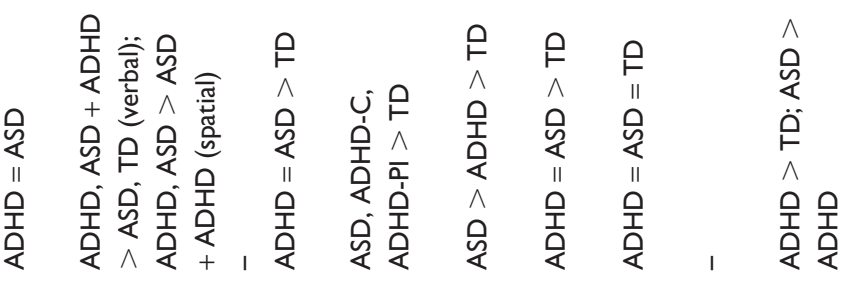

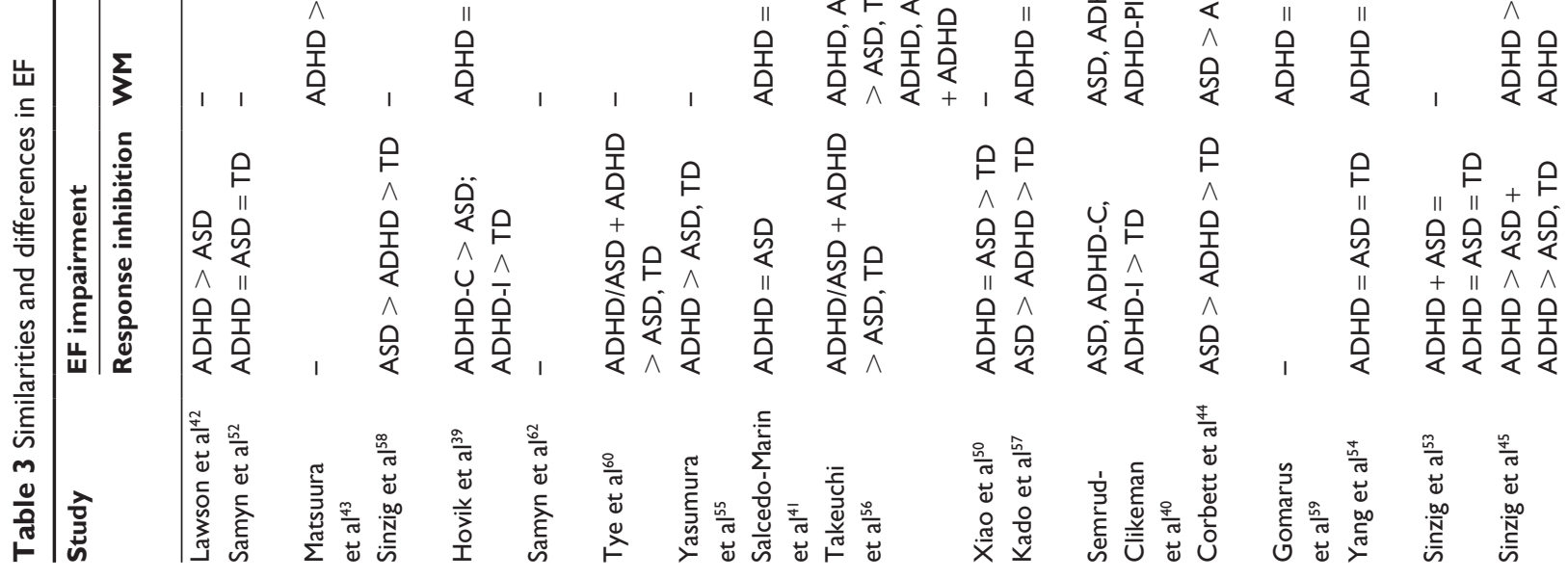




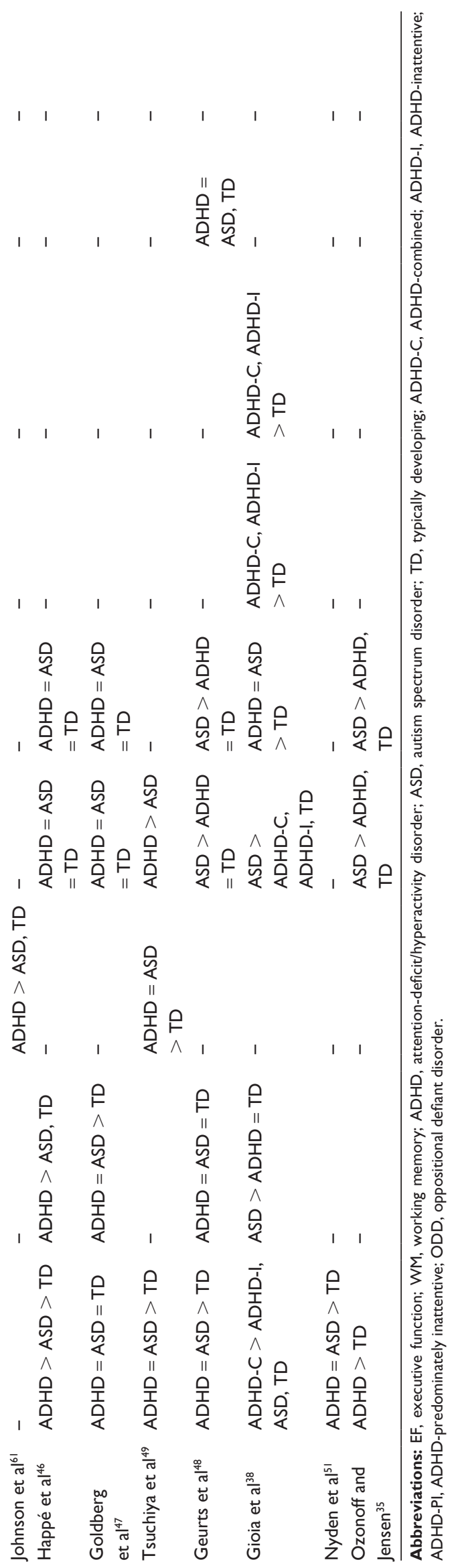

patients demonstrated more impairment in inhibitory control compared to the ASD patients. ${ }^{35,42,55}$ Two studies supported that children with ADHD-C tend to have more inhibition problem compared to the ADHD-I and ASD groups. ${ }^{38,39}$ Two studies reported that on the inhibition task, the ADHD group appeared more impaired than the ASD + ADHD, ASD, and TD groups, whereas the ASD + ADHD group performed worse than the TD and ASD groups. ${ }^{45,56}$ In three studies, the ASD group appeared more impaired than the ADHD and the TD groups on almost all variables that regarded the inhibition task..$^{44,57,58}$

\section{Working memory}

Four studies detected more WM impairment in ASD and ADHD groups when compared with the TD group. $39,40,57,59$ No significant differences between the ADHD, ASD, and TD groups in WM were detected in four studies. ${ }^{41,48,50,54}$ Two studies showed that children with ASD had poor performance relative to the ADHD and TD groups in WM. ${ }^{38,44}$ The ADHD group showed striking deficits on a spatial WM task compared to ASD and TD groups in one study. ${ }^{46}$ One study found only differences between ADHD and TD groups ${ }^{43}$ Both verbal memory and visuospatial memory were investigated in one study, finding that the ADHD and ASD + ADHD subjects had negative effects on verbal WM, while impairments in visuospatial WM were detected in the ADHD and ASD groups but not in the ASD + ADHD group. ${ }^{56}$ One study reported more WM impairment in ADHD and $\mathrm{ASD}+\mathrm{ADHD}$ groups compared with ASD and TD groups. ${ }^{60}$ One study showed WM impairment in ASD and ADHD groups; however, only the ADHD group reported more deficits compared to the ASD + ADHD group. ${ }^{45}$

\section{Flexibility}

Six studies reported that ASD children have more difficulty with flexibility dimension than those with ADHD. $35,38,42,44,48,57$ In three studies, no significant differences in flexibility performance were observed among ASD, ADHD, and TD groups. ${ }^{46,47,54}$ Greater deficiency in flexibility in ADHD children compared to the ASD children was reported in two studies. ${ }^{49,58}$ In one study, the ASD + ADHD group appeared more impaired than the ASD and TD groups in the flexibility task. ${ }^{45}$ In one study, ADHD-C and ASD children reported more flexibility impairment compared to ADHD-I and TD children. ${ }^{40}$

\section{Attention}

Three studies reported more impairment in attention skill in ASD and ADHD children compared to the TD children. ${ }^{44,49,59}$ 
No significant differences between the ASD and ADHD groups on the scores of sustained and selective attention were detected in two studies. ${ }^{41,43}$ Two studies showed that ASD + ADHD and ADHD groups tend to have more attention problem compared to the ASD group..$^{53,60}$ Two studies found that children with ADHD demonstrated clear deficits in sustained attention when compared to ASD and TD children. ${ }^{52,61}$ Only one study found no difference in attention performance among ASD, ADHD, and TD groups. ${ }^{62}$ On the contrary, another study showed that the ASD group had a significantly worse performance in sustained attention compared to the ADHD and TD groups. ${ }^{53}$

\section{Planning}

No significant differences on measures of planning across the ASD, ADHD, and TD groups were found in three studies. ${ }^{44,46,47}$ Three studies detected more deficit in planning skills in ASD and ADHD individuals when compared to TD individuals. ${ }^{38,39,60}$ In two studies, the ASD group showed more difficulties with cognitive planning compared to children with ADHD and the healthy control group. ${ }^{35,48}$ One study reported that $\mathrm{ASD}$ and $\mathrm{ASD}+\mathrm{ADHD}$ groups have more planning deficit compared to TD individuals. ${ }^{45}$

\section{Monitoring}

One study found no differences in monitoring between the ASD and ADHD groups; however, both groups showed more deficit compared to the TD individuals. ${ }^{39}$ One study suggested that impaired conflict monitoring is more conspicuous in ASD and ASD + ADHD individuals than in ADHD and TD individuals. ${ }^{60}$ One study reported that ASD children have more monitoring deficit compared to ADHD and TD children. ${ }^{40}$ ADHD-I and ADHD-C children reported more impairment in monitoring than TD children in one study. ${ }^{38}$

\section{Preparatory processing}

One study showed that children with ASD had poorer performance on preparatory processing compared to ASD + ADHD, ADHD, and TD children. ${ }^{60}$ Another study showed no differences between the ASD and ADHD groups in preparatory processing. ${ }^{41}$ ADHD-I and ADHD-C children reported more impairment in preparatory processing compared to the TD children in one study. ${ }^{38}$

\section{Fluency}

No significant differences on measures of fluency across the ASD and ADHD groups were found in two studies; ${ }^{44,48}$ however, one of these ${ }^{48}$ revealed that ASD and ADHD groups were associated with more EF deficits in verbal fluency than TD counterparts.

\section{Concept formation}

Only one study examined the ability of concept formation and found that both ADHD and ASD individuals obtained lower scores using WCST compared to TD individuals, suggesting an inadequate function in these individuals concerning concept formation. ${ }^{57}$

\section{Discussion}

This systematic review identified 26 studies that compared EFs (inhibition, WM, flexibility, attention, planning, monitoring, preparatory processing, fluency, and concept formation) in ASD and ADHD children, and five of these studies also included ASD + ADHD patients. The results of these studies were not unique and often contradictory, probably due to differences in sample characteristics (number of participants, diagnosis-related groups, age, and IQ level) and assessment methodology. Nevertheless, similarities and differences between ASD, ADHD, ASD + ADHD, and TD groups were highlighted by the studies reviewed.

Overall, the similarities between neurocognitive profiles of ASD, ADHD, and ASD + ADHD individuals include several areas of EF such as attention, WM, and fluency. In most of the studies, the dysfunction in attention was frequently observed in all clinical groups (ASD, ADHD, and ASD + ADHD) compared to the TD group. Some studies reported that the severity of the attention dysfunction is greater in the ADHD and ASD + ADHD groups than the ASD and TD groups. ${ }^{53,60}$ Moreover, investigating various domains of attention, the ADHD children differed from the healthy children especially on the sustained and divided attention tasks, whereas children with ASD + ADHD had difficulties in divided attention and alertness tasks. ${ }^{53}$ Studies examining WM suggest similar performances in ASD, ADHD, and ASD + ADHD individuals..$^{39,40,57,59}$ Nevertheless, both ADHD and ASD + ADHD groups needed more time to perform the WM task, while the ASD children made more errors than the healthy children. ${ }^{56}$ With regard to fluency, studies indicate that there are no significant differences across the ASD and ADHD groups, but both groups gave fewer correct responses than the TD group in this semantic category. ${ }^{44,48}$

In contrast, EF impairments, such as flexibility, planning, and response inhibition, appear to be distinctive between ASD, ADHD, and ASD + ADHD groups. Children with ASD and ASD + ADHD appear to be characterized by cognitive flexibility and planning deficits. In fact, the majority of the studies 
included in this review support for more deficit in cognitive flexibility in ASD than in ADHD, reporting for the ASD group a slower mean reaction time and a higher percentage of perseverative responses. ${ }^{42}$ Additionally, the ASD + ADHD group showed difficulty with test duration of flexibility task compared to the control and the ASD groups. ${ }^{45}$ With regard to planning, the ASD and ASD + ADHD groups showed more difficulties compared to the ADHD and TD children. ${ }^{45,48}$ Some authors found differences in the mean subsequent thinking time between ASD children compared to the ADHD and TD children, thus suggesting that planning difficulties, for ASD individuals, might be less a problem of comprehension than of speed (more a problem of speed rather than an issue of comprehension). ${ }^{35,48}$ Furthermore, the ASD + ADHD group was characterized by an impairment in duration of the planning task, while the ASD group showed a lower performance to initial thinking time and the mean subsequent thinking time. There are evidences showing that response inhibition appears to be more impaired in the ADHD and ASD + ADHD groups than in the ASD and TD groups. ${ }^{50,56,60}$ The ADHD and ASD + ADHD children make more errors of omission and commission compared to the ASD and healthy control children. ${ }^{45}$
Finally, there are few studies that have investigated impairment in monitoring, preparatory process, and concept formation. The results in these specific EF domains appear to be too contradictory to identify any similarities or differences between ASD, ADHD, and ASD + ADHD groups. The only common result among these studies is that the clinical groups reported greater impairment in monitoring, preparatory process, and concept formation than the group of healthy children.

In Figure 1, we represent the similarities and differences in executive functioning between ASD, ADHD, and ASD + ADHD groups.

\section{Limitations}

This review should be considered in the light of its limitations. The discrepancy in the results in the same EF domain could be mainly attributed to the use of different assessment tools. Many studies of EF currently use traditional neuropsychological EF measures that tap multiple aspects of EF as well as non-EF abilities. Although these tasks may be useful for screening individuals for severe EF deficits, they are too broad to answer

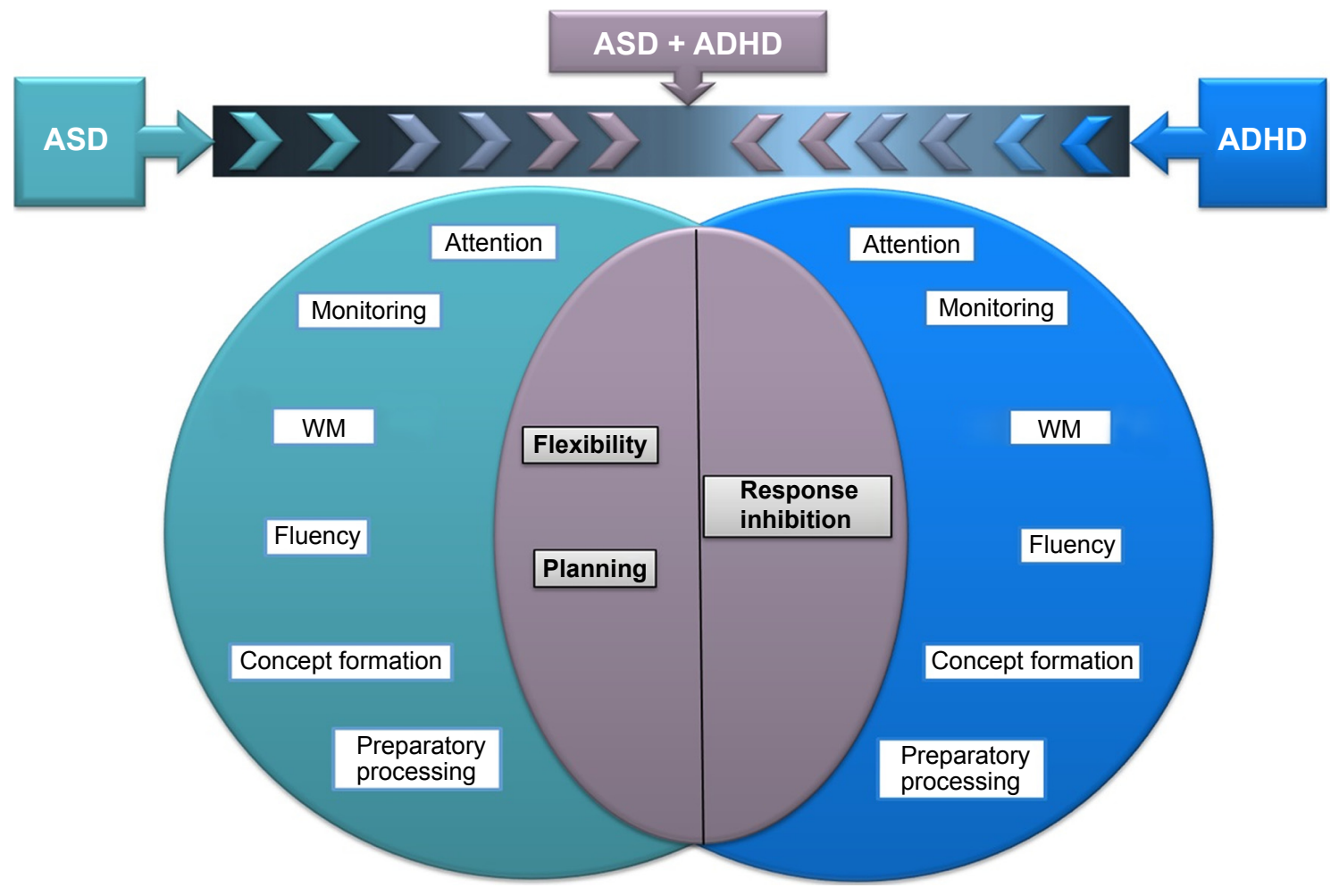

Figure I Similarities and differences in executive functioning between ASD, ADHD, and ASD + ADHD groups.

Notes: The ASD + ADHD group appeared to share impairment in the flexibility and planning with the ASD group, while it shares the response inhibition deficit with the ADHD group. Conversely, deficit in attention, WM, preparatory processes, fluency, and concept formation does not appear to be distinctive in discriminating from ASD, $A D H D$, or ASD + ADHD group.

Abbreviations: ASD, autism spectrum disorder; ADHD, attention-deficit/hyperactivity disorder; WM, working memory. 
fine-grained questions about specific aspects of EF that might be implicated in ASD or ADHD. Although there is no gold standard for the evaluation of EFs, ${ }^{63}$ the progress of theories and models of EFs, along with the new computerized assessment tests (which focus more on the theoretical account deficits below specific components), could facilitate a more accurate, sensitive, and specific performance evaluation of EF.

\section{Conclusion}

This article reviewed 26 studies that examined EF comparing ASD and ADHD children. In light of the findings set out in this review, the ASD + ADHD group appears to share impairments in flexibility and planning with the ASD group, while it shares the response inhibition deficit with the ADHD group (Figure 1). Conversely, deficit in attention, WM, preparatory processes, fluency, and concept formation does not appear to be distinctive in discriminating from ASD, ADHD, or ASD+ ADHD group. These findings are in line with the new criteria of the Diagnostic and Statistical Manual of Mental Disorders, Fifth Edition, where the diagnoses of ASD and ADHD are no longer mutually exclusive. In fact, on the basis of neurocognitive endophenotype, the common co-occurrence of EF deficits seems to reflect an additive comorbidity, rather than a separate condition with distinct impairments. The identification of neurocognitive endophenotype in children with ASD, ADHD or ASD + ADHD could play an important role for the treatment implication because EF cognitive training may change the underlying neural mechanisms to improve the real-world function or clinical symptoms. Nonetheless, the definition of the combined phenotype (ASD + ADHD) needs to integrate genetic, neuroimaging, neurocognitive, and clinical evidences.

\section{Disclosure}

The authors report no conflicts of interest in this work.

\section{References}

1. Miyake A, Friedman NP. The nature and organization of individual differences in executive functions: four general conclusions. Curr Dir Psychol Sci. 2012;21(1):8-14.

2. Ozonoff S. Executive functions in autism. In: Schopler E, Mesibov G, editors. Learning and Cognition in Autism. New York: Plenum Press; 1995:199-219.

3. Ozonoff S, Pennington BF, Rogers SJ. Executive function deficits in high-functioning autistic individuals: relationship to theory of mind. J Child Psychol Psychiatry. 1991;32(7):1081-1105.

4. Russell J, editor. How executive disorders can bring about an inadequate "theory of mind". Autism as an Executive Disorder. Oxford: Oxford University Press; 1997:256-304.

5. Barkley RA. Behavioral inhibition, sustained attention, and executive functions: constructing a unifying theory of ADHD. Psychol Bull. 1997; 121(1):65-94.
6. Biederman J, Monuteaux MC, Doyle AE, et al. Impact of executive function deficits and attention-deficit/hyperactivity disorder (ADHD) on academic outcomes in children. J Consult Clin Psychol. 2004;72(5):757-766.

7. Nigg JT, Blaskey LG, Huang-Pollock CL, Rappley MD. Neuropsychological executive functions and DSM-IV ADHD subtypes. $J$ Am Acad Child Adolesc Psychiatry. 2002;41(1):59-66.

8. Willcutt EG, Doyle AE, Nigg JT, Faraone SV, Pennington BF. Validity of the executive function theory of attention-deficit/hyperactivity disorder: a meta-analytic review. Biol Psychiatry. 2005;57(11):1336-1346.

9. Craig F, Lamanna AL, Margari F, Matera E, Simone M, Margari L. Overlap between autism spectrum disorders and attention deficit hyperactivity disorder: searching for distinctive/common clinical features. Autism Res. 2015;8(3):328-337.

10. Grzadzinski R, Di Martino A, Brady E, et al. Examining autistic traits in children with ADHD: does the autism spectrum extend to ADHD? $J$ Autism Dev Disord. 2011;41(9):1178-1191.

11. Simonoff E, Pickles A, Charman T, Chandler S, Loucas T, Baird G. Psychiatric disorders in children with autism spectrum disorders: prevalence, comorbidity, and associated factors in a population-derived sample. J Am Acad Child Adolesc Psychiatry. 2008;47(8):921-929.

12. Rommelse NN, Franke B, Geurts HM, Hartman CA, Buitelaar JK. Shared heritability of attention-deficit/hyperactivity disorder and autism spectrum disorder. Eur Child Adolesc Psychiatry. 2010;19(3):281-295.

13. Ronald A, Simonoff E, Kuntsi J, Asherson P, Plomin R. Evidence for overlapping genetic influences on autistic and ADHD behaviours in a community twin sample. J Child Psychol Psychiatry. 2008;49(5): 535-542.

14. Taurines R, Schwenck C, Westerwald E, Sachse M, Siniatchkin M, Freitag C. ADHD and autism: differential diagnosis or overlapping traits? A selective review. Atten Defic Hyperact Disord. 2012;4(3): 115-139.

15. Croen LA, Grether JK, Yoshida CK, Odouli R, Hendrick V. Antidepressant use during pregnancy and childhood autism spectrum disorders. Arch Gen Psychiatry. 2011;68(11):1104-1112.

16. Kroger A, Hanig S, Seitz C, Palmason H, Meyer J, Freitag CM. Risk factors of autistic symptoms in children with ADHD. Eur Child Adolesc Psychiatry. 2011;20(11-12):561-570.

17. Lyall K, Pauls DL, Spiegelman D, Ascherio A, Santangelo SL. Pregnancy complications and obstetric suboptimality in association with autism spectrum disorders in children of the Nurses' Health Study II. Autism Res. 2012;5(1):21-30.

18. Brieber S, Neufang S, Bruning N, et al. Structural brain abnormalities in adolescents with autism spectrum disorder and patients with attention deficit/hyperactivity disorder. J Child Psychol Psychiatry. 2007;48(12):1251-1258.

19. Christakou A, Murphy CM, Chantiluke K, et al. Disorder-specific functional abnormalities during sustained attention in youth with Attention Deficit Hyperactivity Disorder (ADHD) and with autism. Mol Psychiatry. 2013;18(2):236-244.

20. Holtmann M, Bolte S, Poustka F. Attention deficit hyperactivity disorder symptoms in pervasive developmental disorders: association with autistic behavior domains and coexisting psychopathology. Psychopathology. 2007;40(3):172-177.

21. Ronald A, Edelson LR, Asherson P, Saudino KJ. Exploring the relationship between autistic-like traits and ADHD behaviors in early childhood: findings from a community twin study of 2-year-olds. J Abnorm Child Psychol. 2010;38(2):185-196.

22. Leitner Y. The co-occurrence of autism and attention deficit hyperactivity disorder in children - what do we know? Front Hum Neurosci. 2014;8:268.

23. Ghezzo A, Guerini FR, Bolognesi E, et al. Neuropsycological gender differences in healthy individuals and in pediatric neurodevelopmental disorders. A role for SNAP-25. Med Hypotheses. 2009;73(6): 978-980.

24. Braida D, Guerini FR, Ponzoni L, et al. Association between SNAP-25 gene polymorphisms and cognition in autism: functional consequences and potential therapeutic strategies. Transl Psychiatry. 2015;5:e500. 
25. Guerini FR, Bolognesi E, Chiappedi M, et al. SNAP-25 single nucleotide polymorphisms are associated with hyperactivity in autism spectrum disorders. Pharmacol Res. 2011;64(3):283-288.

26. Pennington BF, Ozonoff S. Executive functions and developmental psychopathology. J Child Psychol Psychiatry. 1996;37(1):51-87.

27. Milich RB, Balentine AC, Lynam DR. ADHD combined type and ADHD predominantly inattentive type are distinct and unrelated disorders. Clinical Psychology: Science and Practice. 2001;8:463-488.

28. Gargaro BA, Rinehart NJ, Bradshaw JL, Tonge BJ, Sheppard DM. Autism and ADHD: how far have we come in the comorbidity debate? Neurosci Biobehav Rev. 2011;35(5):1081-1088.

29. Ahmadi N, Goodarzi MA, Hadianfard H, et al. Comparing iconic memory in children with and without attention deficit hyperactivity disorder. Iran J Psychiatry. 2013;8(3):131-137.

30. Hughes C, Russell J, Robbins TW. Evidence for executive dysfunction in autism. Neuropsychologia. 1994;32(4):477-492.

31. Pascualvaca DM, Fantie BD, Papageorgiou M, Mirsky AF. Attentional capacities in children with autism: is there a general deficit in shifting focus? J Autism Dev Disord. 1998;28(6):467-478.

32. Courchesne E, Townsend J, Akshoomoff NA, et al. Impairment in shifting attention in autistic and cerebellar patients. Behav Neurosci. 1994; 108(5):848-865.

33. Noterdaeme M, Mildenberger K, Minow F, Amorosa H. Evaluation of neuromotor deficits in children with autism and children with a specific speech and language disorder. Eur Child Adolesc Psychiatry. 2002; 11(5):219-225.

34. Brian JA, Tipper SP, Weaver B, Bryson SE. Inhibitory mechanisms in autism spectrum disorders: typical selective inhibition of location versus facilitated perceptual processing. J Child Psychol Psychiatry. 2003;44(4):552-560

35. Ozonoff S, Jensen J. Brief report: specific executive function profiles in three neurodevelopmental disorders. J Autism Dev Disord. 1999; 29(2):171-177.

36. Hill E, Berthoz S, Frith U. Brief report: cognitive processing of own emotions in individuals with autistic spectrum disorder and in their relatives. J Autism Dev Disord. 2004;34(2):229-235.

37. O'Hearn K, Asato M, Ordaz S, Luna B. Neurodevelopment and executive function in autism. Dev Psychopathol. 2008;20(4):1103-1132.

38. Gioia GA, Isquith PK, Kenworthy L, Barton RM. Profiles of everyday executive function in acquired and developmental disorders. Child Neuropsychol. 2002;8(2):121-137.

39. Hovik KT, Egeland J, Isquith PK, et al. Distinct patterns of everyday executive function problems distinguish children with Tourette syndrome from children with ADHD or autism spectrum disorders. J Atten Disord. Epub 2014 Sep 24.

40. Semrud-Clikeman M, Walkowiak J, Wilkinson A, Butcher B. Executive functioning in children with Asperger syndrome, ADHD-combined type, ADHD-predominately inattentive type, and controls. J Autism Dev Disord. 2010;40(8):1017-1027.

41. Salcedo-Marin MD, Moreno-Granados JM, Ruiz-Veguilla M, Ferrin M. Evaluation of planning dysfunction in attention deficit hyperactivity disorder and autistic spectrum disorders using the zoo map task. Child Psychiatry Hum Dev. 2013;44(1):166-185.

42. Lawson RA, Papadakis AA, Higginson CI, et al. Everyday executive function impairments predict comorbid psychopathology in autism spectrum and attention deficit hyperactivity disorders. Neuropsychology. 2015;29(3):445-453.

43. Matsuura N, Ishitobi M, Arai S, et al. Distinguishing between autism spectrum disorder and attention deficit hyperactivity disorder by using behavioral checklists, cognitive assessments, and neuropsychological test battery. Asian J Psychiatr. 2014;12:50-57.

44. Corbett BA, Constantine LJ, Hendren R, Rocke D, Ozonoff S. Examining executive functioning in children with autism spectrum disorder, attention deficit hyperactivity disorder and typical development. Psychiatry Res. 2009;166(2-3):210-222.
45. Sinzig J, Morsch D, Bruning N, Schmidt MH, Lehmkuhl G. Inhibition, flexibility, working memory and planning in autism spectrum disorders with and without comorbid ADHD-symptoms. Child Adolesc Psychiatry Ment Health. 2008;2(1):4.

46. Happé F, Booth R, Charlton R, Hughes C. Executive function deficits in autism spectrum disorders and attention-deficit/hyperactivity disorder: examining profiles across domains and ages. Brain Cogn. 2006; 61(1):25-39.

47. Goldberg MC, Mostofsky SH, Cutting LE, et al. Subtle executive impairment in children with autism and children with ADHD. J Autism Dev Disord. 2005;35(3):279-293.

48. Geurts HM, Verte S, Oosterlaan J, Roeyers H, Sergeant JA. How specific are executive functioning deficits in attention deficit hyperactivity disorder and autism? J Child Psychol Psychiatry. 2004;45(4):836-854.

49. Tsuchiya E, Oki J, Yahara N, Fujieda K. Computerized version of the Wisconsin card sorting test in children with high-functioning autistic disorder or attention-deficit/hyperactivity disorder. Brain Dev. 2005;27(3):233-236.

50. Xiao T, Xiao Z, Ke X, et al. Response inhibition impairment in high functioning autism and attention deficit hyperactivity disorder: evidence from near-infrared spectroscopy data. PLoS One. 2012;7(10):e46569.

51. Nyden A, Gillberg C, Hjelmquist E, Heiman M. Executive function/ attention deficits in boys with Asperger syndrome, attention disorder and reading/writing disorder. Autism. 1999;3:213-228.

52. Samyn V, Roeyers H, Bijttebier P, Rosseel Y, Wiersema JR. Assessing effortful control in typical and atypical development: are questionnaires and neuropsychological measures interchangeable? A latent-variable analysis. Res Dev Disabil. 2014;36C:587-599.

53. Sinzig J, Bruning N, Morsch D, Lehmkuhl G. Attention profiles in autistic children with and without comorbid hyperactivity and attention problems. Acta Neuropsychiatr. 2008;20(4):207-215.

54. Yang J, Zhou S, Yao S, Su L, McWhinnie C. The relationship between theory of mind and executive function in a sample of children from mainland China. Child Psychiatry Hum Dev. 2009;40(2):169-182.

55. Yasumura A, Kokubo N, Yamamoto H, et al. Neurobehavioral and hemodynamic evaluation of Stroop and reverse Stroop interference in children with attention-deficit/hyperactivity disorder. Brain Dev. 2014;36(2):97-106

56. Takeuchi A, Ogino T, Hanafusa K, et al. Inhibitory function and working memory in attention deficit/hyperactivity disorder and pervasive developmental disorders: does a continuous cognitive gradient explain ADHD and PDD traits? Acta Med Okayama. 2013;67(5):293-303.

57. Kado Y, Sanada S, Yanagihara M, et al. Executive function in children with pervasive developmental disorder and attention-deficit/ hyperactivity disorder assessed by the Keio version of the Wisconsin card sorting test. Brain Dev. 2012;34(5):354-359.

58. Sinzig J, Vinzelberg I, Evers D, Lehmkuhl G. Executive function and attention profiles in preschool and elementary school children with autism spectrum disorders or ADHD. Int J Dev Disabil. 2014;60(3):144-154.

59. Gomarus HK, Wijers AA, Minderaa RB, Althaus M. ERP correlates of selective attention and working memory capacities in children with ADHD and/or PDD-NOS. Clin Neurophysiol. 2009;120(1):60-72.

60. Tye C, Asherson P, Ashwood KL, Azadi B, Bolton P, McLoughlin G. Attention and inhibition in children with ASD, ADHD and co-morbid ASD + ADHD: an event-related potential study. Psychol Med. 2014; 44(5):1101-1116.

61. Johnson KA, Robertson IH, Kelly SP, et al. Dissociation in performance of children with ADHD and high-functioning autism on a task of sustained attention. Neuropsychologia. 2007;45(10):2234-2245.

62. Samyn V, Wiersema JR, Bijttebier P, Roeyers H. Effortful control and executive attention in typical and atypical development: an event-related potential study. Biol Psychol. 2014;99:160-171.

63. Chan RC, Shum D, Toulopoulou T, Chen EY. Assessment of executive functions: review of instruments and identification of critical issues. Arch Clin Neuropsychol. 2008;23(2):201-216. 


\section{Publish your work in this journal}

Neuropsychiatric Disease and Treatment is an international, peerreviewed journal of clinical therapeutics and pharmacology focusing on concise rapid reporting of clinical or pre-clinical studies on a range of neuropsychiatric and neurological disorders. This journal is indexed on PubMed Central, the 'PsycINFO' database and CAS, and is the official journal of The International Neuropsychiatric Association (INA). The manuscript management system is completely online and includes a very quick and fair peer-review system, which is all easy to use. Visit http://www.dovepress.com/testimonials.php to read real quotes from published authors.

\footnotetext{
Submit your manuscript here: http://www.dovepress.com/neuropsychiatric-disease-and-treatment-journal
} 